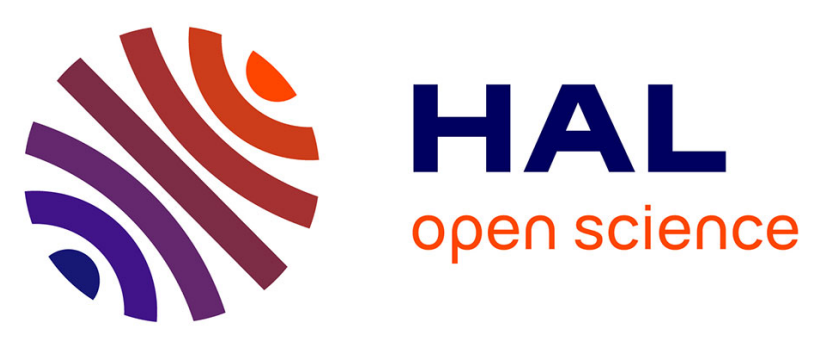

\title{
Organized Hybrid Molecular Films from Natural Phospholipids and Synthetic Block Copolymers: A Physicochemical Investigation
}

Arianna Balestri, Leonardo Chiappisi, Costanza Montis, Samantha Micciulla, Barbara Lonetti, Debora Berti

\section{To cite this version:}

Arianna Balestri, Leonardo Chiappisi, Costanza Montis, Samantha Micciulla, Barbara Lonetti, et al.. Organized Hybrid Molecular Films from Natural Phospholipids and Synthetic Block Copolymers: A Physicochemical Investigation. Langmuir, 2020, 36 (37), pp.10941-10951. 10.1021/acs.langmuir.0c01544 . hal-02986630

\section{HAL Id: hal-02986630 https://hal.science/hal-02986630}

Submitted on 19 Nov 2020

HAL is a multi-disciplinary open access archive for the deposit and dissemination of scientific research documents, whether they are published or not. The documents may come from teaching and research institutions in France or abroad, or from public or private research centers.
L'archive ouverte pluridisciplinaire HAL, est destinée au dépôt et à la diffusion de documents scientifiques de niveau recherche, publiés ou non, émanant des établissements d'enseignement et de recherche français ou étrangers, des laboratoires publics ou privés. 


\title{
Organized hybrid molecular films from natural
}

\author{
phospholipids and synthetic block copolymers: a
}

\section{physicochemical investigation}

Arianna Balestri, Leonardo Chiappisi, Costanza Montis, Samantha Micciulla, Barbara Lonetti and Debora Berti

Department of Chemistry “Ugo Schiff” and CSGI, via della Lastruccia 3-13, 50019, Florence, Italy.

Institut Laue Langevin, 71 avenue des Martyrs, 38000 Grenoble, France.

Laboratoire des IMRCP, Université de Toulouse, CNRS UMR 5623, Université Toulouse IIIPaul Sabatier, 118 route de Narbonne, F-31062, Toulouse Cedex 9, France.

\begin{abstract}
In the last few years, hybrid lipid-copolymer assemblies have attracted increasing attention as possible $2 \mathrm{D}$ membrane platforms combining the bio-relevance of the lipid building blocks with the stability and chemical tunability of copolymers. The relevance of these systems varies from
\end{abstract}


fundamental studies on biological membrane-related phenomena to the construction of $2 \mathrm{D}$ complex devices for material science and biosensor technology. Both the fundamental understanding and the application of hybrid lipid-copolymer supported bilayers require a thorough physicochemical comprehension and structural control. Herein, we report a comprehensive physicochemical and structural characterization of hybrid monolayers at the air/water interface and of solid-supported hybrid membranes constituted by 1,2-dipalmitoyl-sn-glycero-3phosphocholine (DPPC), and the block copolymer poly(butadiene-b-ethyleneoxide) (PBD-bPEO). Hybrid supported lipid bilayers (HSLBs) with variable copolymer content were prepared through spontaneous rupture and fusion of hybrid vesicles onto a hydrophilic substrate. The properties of the thin films and the parent vesicles were probed through dynamic light scattering (DLS), differential scanning calorimetry (DSC), optical ellipsometry, quartz crystal microbalance with dissipation monitoring (QCM-D) and confocal scanning laser microscopy (CSLM). Stable, hybrid lipid/copolymer systems were obtained for a copolymer content of $10-65 \%$ mol. In particular, DSC and CSLM show lateral phase separation in these hybrid systems. These results improve our fundamental understanding on HSLBs, which is necessary for future applications of hybrid systems as biomimetic membranes or as drug delivery systems, with additional properties with respect to phospholipid liposomes.

\section{INTRODUCTION}

Phospholipids are the primary structural components of biological membranes, and their selfassembly into fluid bilayers act as a barrier and exchange site between the internal and external cellular compartments. In aqueous solution, both natural and synthetic phospholipids can spontaneously assemble into bilayered closed structures, leading to the formation of liposomes.[1] Due to their high biocompatibility and their structural similarity with plasma membranes, 
liposomes have been widely used both as drug delivery systems for applications in nanomedicine, or as biomimetic membranes for fundamental studies on cell membrane-related phenomena in simplified conditions.[2][3]

Among the multiple applications of lipid assemblies, their 2D projection on a support to form supported lipid bilayers (SLBs) has been widely exploited, mainly to build mimics of biological membranes, for biophysical studies on cell membranes-related phenomena. [4] Recently, thanks to the progress in surface patterning methods, microfluidics or organic electronics, supported lipid films have also been highlighted for their potential as substrate-mediated soft devices. [5] Bilayer deposition onto solid surfaces has the advantage to preserve the native lipid state, while providing a robust and stable platform to characterize the system with sensitive surface techniques, including quartz crystal microbalance with dissipation monitoring (QCM-D), optical ellipsometry, atomic force microscopy (AFM) and Neutron or X-Ray Reflectivity (NR or XRR).[6] [7][8]

If on the one hand, lipid assemblies can adapt to external stimuli and environmental changes, i.e. $\mathrm{pH}$ or ionic strength, they are, on the other hand, often characterized by mechanical fragility and lack of stability. In addition, the synthetic versatility and possibility to conjugate functional moiety to phospholipids are limited, thereby narrowing their applicative range.

A totally synthetic alternative to phospholipids is represented by amphiphilic block copolymers, which can self-assemble in robust vesicular structures called polymersomes.[9][10] Due to the higher chemical versatility of copolymers with respect to phospholipids and to the higher stability with respect to liposomes, polymersomes gained growing interest in membrane research, both as biomimetic systems and as vectors for drug delivery.[11][12][13] Polymer bilayers offer significant chemical, spatial and physicochemical variability, e.g. their membrane thicknesses 
typically vary from 8 to $50 \mathrm{~nm}$, compared to the $4-5 \mathrm{~nm}$ thickness typical of phospholipid bilayers.[14] Besides, the wide choice of block chemistry and the possibility of varying both blocks lengths allow to design structures with the desired tuneable properties.[6] If, on the one hand, polymer bilayers exhibit a higher mechanical stability with respect to lipid ones, their membranes are characterized by a low permeability, low lateral mobility and minor biocompatibility, which limits their use in biological studies.[15]

In this context, hybrid bilayers, obtained as a mixture of lipids and copolymers, have the potential not only to merge the advantages of lipo- and polymers membranes [16][17][18][19] [20] but also to present new biophysical and biochemical properties [21].

In particular, the addition of a copolymer can: (i) improve the stability and mechanical strength of the mixed membrane, compared to the bare lipid one; (ii) allow a wide range tunability of the thickness of the membrane, which could more easily host hydrophobic species (as hydrophobic nanoparticles or membrane proteins); (iii) strongly influence membrane transport properties, curvature and in some case induce channels in the lipid membrane; (iv) promote the formation of complex membranes, with lateral phase separation and coexistence of domains of different fluidity (see Figure 1.). The strategy of introducing heterogeneities into membrane to impart complex, multifunctional properties is widely exploited by nature, where lateral membrane inhomogeneities mediate various cellular processes in cells. From a material science standpoint, new sophisticated devices with domains organized in a controlled way, responsive or differently functionalized, with a spatial and temporal control of the properties, are fascinating. 


$$
\{\text { Copolymer }
$$

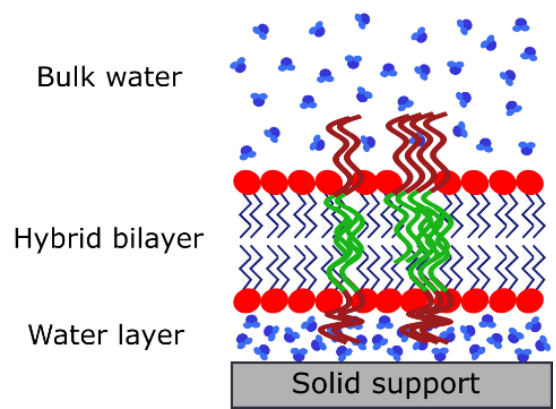

Figure 1. Schematic diagram of a solid supported hybrid lipid-copolymer bilayer.

While the formation and the physicochemical, structural characterization of SLBs has been addressed in many studies over the years, the inclusion of amphiphilic copolymers into SLBs, to form hybrid lipid-copolymer supported bilayers (HSLBs) has been developed only very recently. [21] [22] [23]To the aim of designing biologically relevant model membranes, hybrid lipidcopolymer systems have been studied as a platform for direct membrane proteins insertion in free-standing membranes or monolayers. [6][24][25]

In the present work, we performed a complete physicochemical characterization of HLSBs made of poly(butadiene-block-ethyleneoxide) (PBD-b-PEO) and 1,2-dipalmitoyl-sn-glycero-3phosphocholine (DPPC). DPPC, a common component of biological membranes in lungs, is an interesting component for the design of thermoresponsive nanocarriers, thanks to its melting transition close to physiological temperature $\left(\mathrm{T}_{\mathrm{m}}=41^{\circ} \mathrm{C}\right) .[26]$ Recently PBD-b-PEO systems have been proposed for biomedical applications[5], due to the self-assembly into similar lipid structures for the presence of hydrophilic (PEO) and hydrophobic (PBD) groups. The polymer has the ratio of hydrophilic to total mass which falls in the range (29\%-39\%) suitable for creating 
vesicles and a low glass transition temperature $\left(T_{g}=-10^{\circ} \mathrm{C}\right)$ which ensures dispersion and mixing with lipid. [21] Although PBD is not biodegradable, the conjugation with PEO makes the blockcopolymer PBD-b-PEO biocompatible. [27] Based on the hydrophobic effect and the selfassembly of the amphiphilic copolymer, it has been shown that synthetic polymer PBD-b-PEO can be incorporated into lipid bilayers.[21] [22] [23]

In a bilayer structure DPPC and PBD-b-PEO spontaneously self-assemble forming 10-12 nm polymer [21] and $4.4 \mathrm{~nm}$ lipid [28] membranes, respectively.

Previously, the formation of fluid-like inhomogeneities in mixed PBD-b-PEO and DPPC membranes was evidenced at the micro- length scale.[29] In this contribution, the lateral phase separation in lipid-rich and copolymer-rich regions is addressed combining a series of surface techniques in monolayers, supported bilayers, and free-standing bilayers.

The lipid-copolymer interactions have been analysed at the air/water interface through isothermal cycles and at the solid/water interface thorough quartz crystal microbalance with dissipation monitoring (QCM-D) and confocal laser scanning microscopy (CSLM), while their structural properties were investigated using optical ellipsometry at both interfaces.

\section{EXPERIMENTAL SECTION}

\subsection{Materials}

DPPC (1,2-dipalmitoyl-sn-glycero-3-phosphocholine) (DPPC, >99\%) and $\beta$-bodipy(2-(4,4diuoro- 5,7-dimethyl-4-bora-3a,4adiaza-sindacene-3-pentanoyl)-1hexadecanoyl-sn-glycero-3phosphocholine) used for liposomes and supported hybrid bilayers, were purchased from Avanti Polar Lipids, Inc. (Alabaster, AL). The copolymer polybutadiene $\left(\mathrm{M}_{\mathrm{n}}=2500 \mathrm{~g} / \mathrm{mol}\right)$-blockpoly(ethylene oxide) ( $\left.\mathrm{M}_{\mathrm{n}}=1300 \mathrm{~g} / \mathrm{mol}\right)(1,2$ addition butadiene, $89 \%)$ (PBD-b-PEO) and the rhodamine labelled copolymer polybutadiene $\left(\mathrm{M}_{\mathrm{n}}=1200 \mathrm{~g} / \mathrm{mol}\right)$-block-poly(ethyne oxide $)\left(\mathrm{M}_{\mathrm{n}}=\right.$ 
$600 \mathrm{~g} / \mathrm{mol}$ ), RhodPEBD-b-PEO, were purchased from Polymer Source. $\mathrm{NaCl}$ and $\mathrm{CaCl}_{2} \cdot \mathrm{H}_{2} \mathrm{O}$ salts used for solutions' preparation were purchased from Sigma and Merck, respectively.

\subsection{Preparation of vesicles}

Vesicles were prepared with the method of dry film rehydration.[30] Briefly, solutions of the pure lipids, copolymer and lipid/copolymer blends were prepared in chloroform mixing stock solution of $5 \mathrm{mg} / \mathrm{mL}$ DPPC and $5 \mathrm{mg} / \mathrm{mL}$ PBD-b-PEO in $\mathrm{CHCl}_{3}$. The solvent was removed using nitrogen flux to obtain films. Complete solvent removal was achieved by keeping the film under vacuum for 24 hours. Hybrid vesicles were prepared in both aqueous and $\mathrm{NaCl} 0.1 \mathrm{M}$ solutions to determine the effective formation of hybrid DPPC/PBD-b-PEO vesicles as preliminary characterization and as the buffer condition for HSLBs deposition, respectively. Then, $4 \mathrm{~mL}$ of Milli-Q water, $0.1 \mathrm{M} \mathrm{NaCl}$ aqueous solution was added and the film rehydrated through sonication at $50{ }^{\circ} \mathrm{C}$ for 15 minutes, obtaining a final concentration of $1 \mathrm{mg} / \mathrm{mL}$ for all the samples. Aqueous suspensions were extruded 9 times at $50^{\circ} \mathrm{C}$ through $100 \mathrm{~nm}$ pore size polycarbonate membrane filters using an Avanti Mini-Extruder. The dispersions in $\mathrm{NaCl} 0.1 \mathrm{M}$ solution, consisted of large agglomerates, were then been tip sonicated with a Digital Sonifier Model 450 (Branson, Hampton, NH,USA), provided with a Horn Tip (diameter $25.4 \mathrm{~mm}$ ), in an intermittent-pulse mode (5 s), with a power of $40 \mathrm{kHz}$ (amplitude 100\%). Vesicles were formed with a molar ratio of copolymer and lipid: $0 ; 10 \% ; 35 \% ; 65 \%$ and $100 \%$ mol PBD-b-PEO:DPPC.

\subsection{Preparation of supported bilayers}

Solid supported bilayers were prepared by vesicles spontaneous rupture and fusion onto a $\mathrm{Si} / \mathrm{SiO}_{2}$ wafer $2 \mathrm{~cm} \times 2 \mathrm{~cm}$. Before vesicles deposition, the surface of the wafer was made 
hydrophilic with sonication bath for 20 minutes in ethanol solution, nitrogen drying and UV-Ozone cleaning for 15 minutes. SLB were obtained by adding $\mathrm{CaCl}_{2} 10 \mathrm{mM}$ aqueous solution to the dilute $(0.5-1 \mathrm{mg} / \mathrm{mL})$ dispersions of vesicles in $\mathrm{NaCl} 0.1 \mathrm{M}$ solution and subsequently deposited onto silicon substrate at $\mathrm{T}=50^{\circ} \mathrm{C}$ for 30 minutes. After deposition, the substrate was washed 15 times with $1 \mathrm{~mL}$ of Milli-Q water and then cooled to ambient temperature.

\subsection{Hybrid monolayers at a/w interface}

Monolayers at the air/water interface were prepared by depositing chloroform solutions (15-50 $\mu \mathrm{L}$ ) with the following copolymer/lipid molar ratio: $0 \%, 10 \%, 35 \%, 65 \%$ and $100 \%$ mol PBD-bPEO: DPPC ( $1 \mathrm{mg} / \mathrm{mL}$ ) onto a pure Milli-Q water surface (subphase). Experiments were performed after 20 minutes to allow the chloroform to evaporate.

\subsection{Methods}

\subsubsection{Differential scanning calorimetry (DSC)}

Measurements were performed with a micro-DSC III 106 (Setaram, France). Cells made of Hallestoy C (volume of $1 \mathrm{~cm}^{3}$ ) were filled with $\sim 400 \mathrm{mg}$ of hybrid vesicle solution $(2-8 \mathrm{mg} / \mathrm{mL}$ ) and the reference cell with the same amount of $\mathrm{NaCl} 0.1 \mathrm{M}, \mathrm{CaCl}_{2} 10 \mathrm{mM}$ solution. Besides, the copolymer vesicles and liposomes were also measured $(2 \mathrm{mg} / \mathrm{mL})$. During operation, a constant nitrogen flux purged the instrument and scans were performed between $10{ }^{\circ} \mathrm{C}$ and $60{ }^{\circ} \mathrm{C}$ with 3 heating and 2 cooling cycles with a heating rate of $0.5^{\circ} \mathrm{C} / \mathrm{min}$. The data were corrected for the empty cell contribution using pyDSC[Aline Cisse, Judith Peters, Giuseppe Lazzara, Leonardo Chiappisi, "PyDSC: A simple tool to treat differential scanning calorimetry data." Journal of Thermal Analysis and Calorimetry, 2020, 10.1007/s10973-020-09775-9], freely available at 
https://github.com/leonardo-chiappisi/pyDSC, which computes the baseline according to Malakhov et al.[31]

\subsubsection{Dynamic light scattering (DLS)}

Dynamic light scattering (DLS) used to evaluate z-average size and polydispersity of the aqueous suspension vesicles or liposomes, was performed using a Brookhaven Instruments apparatus (BI 900AT correlator and BI 200 SM goniometer). The light source was the second harmonic of a diode Nd:YAG laser, $\lambda=532 \mathrm{~nm}$, Coherent DPY315M-100, linearly polarized in the vertical direction. The normalized intensity time autocorrelation of the scattered light was measured at $90^{\circ}$ and analysed according to the Siegert relationship, which connects the first order or field-normalized autocorrelation function $\mathrm{g}_{1}(\mathrm{q}, \tau)$ to the measured normalized autocorrelation function $\mathrm{g}_{2}(\mathrm{q}, \tau)$ :

$$
g_{2}(q, \tau)=1+\beta\left|g_{1}(q, \tau)\right|^{2}
$$

1)

with $\beta$ spatial coherence factor, which depends on the geometry of the detection system. The field autocorrelation functions were analysed through a cumulant analysis stopped at the second order and through reverse Laplace transform performed with the Contin algorithm [32]. Measurements were performed at $25^{\circ} \mathrm{C}$ three times for each sample diluted to $0.5 \mathrm{mg} / \mathrm{mL}$ to avoid multiple scattering. The reported values are average ones with standard deviation.

\subsubsection{Optical Ellipsometry}


The ellipsometry data were recorded using a phase modulated Picometer Light ellipsometer (Beaglehole Instruments, New Zealand) equipped with a HeNe laser with $\lambda=632.8 \mathrm{~nm}$. Physical information of the sample was extracted using an optical model based on classical electromagnetic theory and the approximation of the sample in terms of parallel optical slabs of defined thicknesses (d) and refractive indices (n). The values of the thickness $d_{i}$ and the refractive index $n$ were evaluated by fitting the experimental angles $\Psi$ and $\Delta$ using the pyEllip python script, freely available at https://github.com/leonardo-chiappisi/pyEllip and provided in the supporting information. The script uses of $1 \mathrm{mfit}[33]$ and tmm[34] python packages. For solid-liquid interface characterization, with a 4 model parallel layers model was applied in order to determine the bilayer thickness d, fixing a refractive thickness value: bulk silicon, $\mathrm{SiO}_{2}$ layer, bilayer and bulk water. For each sample, three measurements at different positions on the sample, were performed at a variable angle in a range between $50^{\circ}-80^{\circ}$.

\subsubsection{Quartz crystal microbalance with dissipation}

Quartz Crystal Microbalance with Dissipation monitoring (QCM-D) was performed with a QSense E4 instrument (Q- Sense, Gothenburg, Sweden), equipped with four flow liquid cells ( 0.5 $\mathrm{mL}$ internal volume), each containing a coated quartz sensor, with a $5 \mathrm{MHz}$ fundamental resonance frequency, mounted horizontally. The active surface of the sensors $\left(\approx 1 \mathrm{~cm}^{2}\right)$ is coated with a thin $\mathrm{SiO}_{2}$ layer $(\approx 100 \mathrm{~nm}$ thick). The sensors were cleaned before use by washing in pure ethanol and bath sonication for 15 minutes, nitrogen drying and finally ozone cleaning for 10 minutes. The experiments were performed at $40^{\circ} \mathrm{C}$ and solvent exchange in the measurement chamber was achieved with a peristaltic pump. The sensors were placed in the chambers and Milli-Q water was 
injected at a low flowrate $(0.1 \mathrm{~mL} / \mathrm{min})$. The fundamental resonance frequencies (f) and corresponding energy dissipation factors (D) were measured for the odd overtones (3st-11th). A stable baseline for both $\mathrm{f}$ and $\mathrm{D}$ of the different harmonics was ensured before injection of the vesicles at a low flowrate $(0.1 \mathrm{~mL} / \mathrm{min})$. The QCM-D curves reported are normalized by the overtone number. The hydrated mass was estimated applying the Sauerbrey relation [35], valid under the approximation of rigid films,

$$
\Delta m=-\frac{C \Delta f}{n}
$$

with mass sensitivity constant $\mathrm{C}=17.7 \mathrm{ng} \mathrm{cm}^{2} \mathrm{~Hz}^{-1}$ for $5 \mathrm{MHz}$ sensor crystal. Each experiment was performed in duplicate.

\subsubsection{Confocal laser scanning microscopy (CLSM)}

Confocal Microscopy was performed on a Leica TCS SP8 Confocal Microscope (Leica Microsystems). $\beta$-bodipy and RhodPBD-b-PEO were excited respectively at $488 \mathrm{~nm}$, with an Ar laser, and $561 \mathrm{~nm}$, with a DPSS 561 laser. The fluorescence was collected with PMTs in the wavelength ranges 498-550 nm and 600-650 nm, for $\beta$-bodipy and RhodPBD-b-PEO, respectively. The fluorescent probes in the vesicle solution were added to a ratio dye of $0.1 \%(\mathrm{w} / \mathrm{w})$. All the measurements were performed at room temperature $\left(\mathrm{T}=25^{\circ} \mathrm{C}\right)$.

\subsubsection{Compression isotherms}


The compression isotherms of pure and hybrid monolayers at the air water interface were measured on a Langmuir trough, 300 x 200 mm, with a Teflon compression barrier (NIMA 611). The surface pressure, $\Pi=\Upsilon_{\mathrm{a} / \mathrm{w}}-\Upsilon_{\mathrm{a} / \mathrm{m}}$, was monitored with a Wilhelmy plate made of filter paper during two compression/expansion cycles, performed with a constant barrier speed of $25 \mathrm{~mm} / \mathrm{min}$. After 20 minutes from the deposition, for the evaporation of chloroform, two isothermal cycles have been applied at constant temperature $\mathrm{T}=21^{\circ} \mathrm{C}$.

\subsubsection{Monolayer surface excess}

The surface excess of pure and hybrid monolayers as a function of surface pressure was determined using a Langmuir trough KSV-Nima, $19.5 \mathrm{~cm}$ x $5 \mathrm{~cm}$, with two symmetrical compression barriers with a constant compression of $1 \mathrm{~mm} / \mathrm{min}$, in combination with the Beaglehole ellipsometer described earlier, at an angle of incidence in a range $51-55^{\circ}$. The air-water interface was characterized using three parallel layers model (bulk water, monolayer, and air), allowing us to monitor the Surface excess $\Gamma$ at determined pressure values with a Wilhlemy plate. Due to the low thickness of the monolayer, optical ellipsometry cannot be used to resolve simultaneously both the film thickness $d$ and its refractive index. However, the surface excess can be determined through this technique [36]:

$$
\Gamma=\frac{d\left(n_{1}-n_{2}\right)}{\frac{\partial n}{\partial c}}
$$

3)

Where $\mathrm{n}_{1}$ and $\mathrm{n}_{2}$ are the refractive index of the monolayer and the aqueous subphase, respectively, $\mathrm{d}$ is the thickness of the monolayer, and $\partial n / \partial c$ is the refractive index increment. Due 
to the low thickness of the thin films, their thickness and refractive index cannot be determined simulataneously, and the surface excess was obtained by fixing the thickness to an arbitrary chosen value. This choice, however, had no sensible effect on the resulting surface excess values obtained. The refractive index increment of the components in water, $\mathrm{dn} / \mathrm{dc}$, was experimentally measured for the reference samples and determined as weight percentage for the hybrid samples reported in the supporting information.

\section{Results and Discussion}

\subsection{Hybrid vesicles}

Due to their amphiphilic nature, DPPC and PBD-b-PEO molecules can individually assemble into vesicular aggregates, forming liposomes and polymersomes, respectively.[37][38] To study the mixing behaviour of the lipid and the synthetic diblock copolymer in vesicle membranes, different molar mixtures between DPPC and PBD-b-PEO were prepared and characterized through dynamic light scattering (DLS) and differential scanning calorimetry (DSC).

As preliminary characterization, with the aim to verify their hybrid nature, vesicles with different copolymer content $(0,35,65$ and $100 \%$ mol PBD-b-PEO) were prepared in aqueous solution by extrusion method and investigated by DLS (Figure 3a). The autocorrelation functions (ACFs) of the scattered intensity were analysed through the cumulant fitting stopped to the second order, highlighting the formation of monodisperse vesicles for all systems: DPPC (Dh $=114 \pm 1 \mathrm{~nm}$, PDI 0.109), hybrid 35\% mol PBD-b-PEO:DPPC (Dh = $98 \pm 1 \mathrm{~nm}$, PDI 0.212), hybrid 65\% mol PBDb-PEO:DPPC $(\mathrm{Dh}=93 \pm 1 \mathrm{~nm}$, PDI 0.226) and pure PBD-b-PEO (Dh $=76.6 \pm 0.5 \mathrm{~nm}$, PDI 0.129). These results suggest that PBD-b-PEO spontaneously self-assemble into vesicles of smaller size (76.6 $\mathrm{nm}$ hydrodynamic diameter) with respect to the mesh size of the extrusion 
membrane $(100 \mathrm{~nm})$, while DPPC vesicles, are, as expected, slightly larger $(114 \mathrm{~nm})$. When mixed, the obtained vesicles are characterized by Z-averaged intermediate size $(98-93 \mathrm{~nm})$, as also clearly visible from the trend of the normalized ACFs reported in Figure 3a, suggesting the successful formation of hybrid copolymer-lipid vesicles.

As the hybrid vesicles have to be used for SLB deposition through vesicle fusion, we decided to characterize them in the buffer of choice for this procedure, $\mathrm{NaCl} 0.1 \mathrm{M}$. Pure and hybrid vesicles of different composition $(0,10,35,65$ and $100 \%$ mol PBD-b-PEO) were prepared in $\mathrm{NaCl} 0.1 \mathrm{M}$ (see Experimental section for details). Vesicles in salt solution consisted of large agglomerates that cannot be extruded but only tip sonicated, creating polydisperse vesicles. The autocorrelation functions are shown in Fig. 3b. Contin method has been applied to analyse the autocorrelation functions of the pure lipid and hybrid dispersions (results shown in Fig. 3c), while cumulant analysis stopped to the second order was applied to the pure polymer dispersion revealing monodisperse polymerosomes with hydrodynamic radius of $104 \pm 6 \mathrm{~nm}$ and PDI 0.174 . This result confirms that PBD-b-PEO copolymer spontaneously tends to self-assemble into relatively monodisperse vesicles, which are only slightly larger than those obtained in milliQ water and prepared by extrusion. Conversely, both DPPC and hybrid systems are characterized by a very broad size distribution. In all cases, stable systems up to two weeks with particle sizes between 50 and $2000 \mathrm{~nm}$ are found. DPPC, being a zwitterionic phospholipid, tends to form multilamellar vesicles of broad size distribution; Contin analysis highlights the presence of two main distinct populations, the first one being centred at around $100 \mathrm{~nm}$ (small vesicles), the second one centred around $1000 \mathrm{~nm}$ (large multilamellar vesicles and/or aggregates). Interestingly, the hybrid systems show an intermediate behaviour between pure PBD-b-PEO vesicles and DPPC vesicles, with the second larger population gradually disappearing as the percentage of copolymer with respect to 
lipid in the hybrid increases (see Figure 3c). This is a further evidence of the effective formation of hybrid lipid/copolymer aggregates.

In summary, DLS data prove that hybrid polydisperse vesicles are formed in $\mathrm{NaCl} 0.1 \mathrm{M}$ solution in all the copolymer range investigated (0-100\% PBD-b-PEO:DPPC) and that the obtained aggregates are likely to be hybrid systems, containing both lipid and copolymer components. These hybrid vesicles, even if polydisperse, are suitable for the formation of HSLB.

In order to investigate more in details the mixing thermodynamics of DPPC and PBD-b-PEO in the hybrid vesicles, we performed DSC experiments on the same systems.

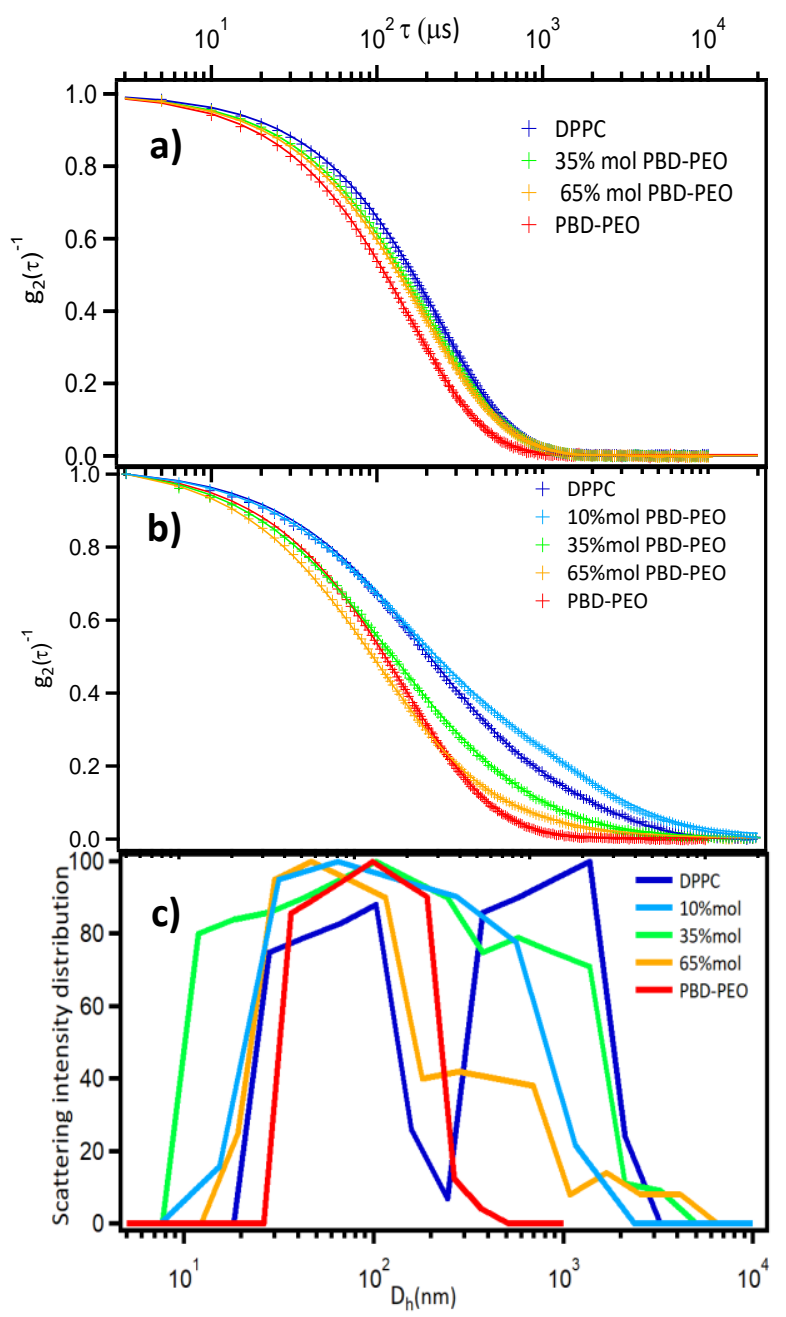


Figure 2. Normalized intensity correlation function of $0,35 \%, 65 \%$ and $100 \%$ mol PBD-b-PEO:DPPC in water (a) and of 0 , $10 \%$, $35 \%, 65 \%$ and 100\% mol PBD-b-PEO:DPPC in NaCl 0.1M (b) and their histograms of the intensity distribution recorded in NaCl solution (c).

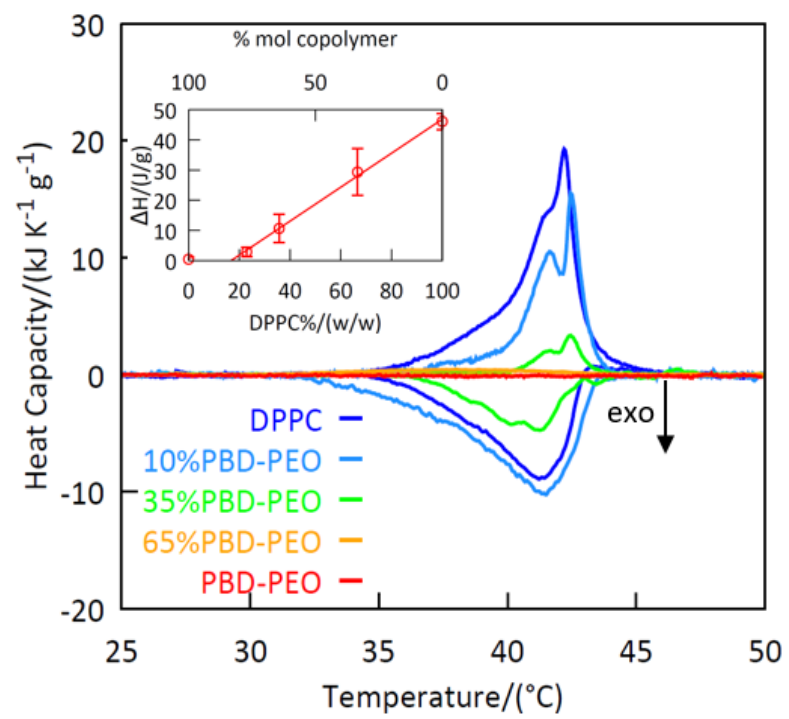

Figure 3. DSC thermograms of 0, 10\%, 35\%, 65\% and 100\% mol PBD-b-PEO:DPPC. The heat capacity normalized by the mass of sample (polymer plus lipid) is reported as a function of temperature. Third heating profile (heat rate of $0.5^{\circ} \mathrm{C} / \mathrm{min}$ ) and second cooling profile (cooling rate of $0.5^{\circ} \mathrm{C} / \mathrm{min}$ ) are reported. The inset represents the dependence of the melting enthalpy from the weight content of lipid in the vesicle mixture.

Table 1. Phase-transition properties of the samples Melting temperature (Tm) (determined as the peak maximum of the heating process) and the melting enthalpy $\Delta H$ normalized by the mass of sample (lipid plus block copolymer).

\begin{tabular}{c|c|ccc}
\hline Sample & $\begin{array}{c}\text { Mass fraction } \\
\text { DPPC }(\%)\end{array}$ & $\mathbf{T m}\left({ }^{\circ} \mathbf{C}\right)$ & $\Delta \mathbf{H}\left(\mathbf{J} / \mathbf{g}_{\text {tot }}\right)$ & $\Delta \mathbf{H}\left(\mathbf{J} / \mathbf{g}_{\text {DPPC }}\right)$ \\
\hline DPPC & 100 & $41 \pm 1$ & $46 \pm 3$ & $46 \pm 3$ \\
\hline $\begin{array}{c}\mathbf{1 0 \%} \% \text { mol PBD- } \\
\text { b-PEO }\end{array}$ & 67 & $41 \pm 1$ & $29 \pm 12$ & $33 \pm 2$ \\
\hline $\begin{array}{c}\mathbf{3 5 \%} \text { mol PBD- } \\
\text { b-PEO }\end{array}$ & 36 & $40 \pm 1$ & $10 \pm 5$ & $27 \pm 13$ \\
\hline $\begin{array}{c}\mathbf{6 5 \%} \% \text { mol PBD- } \\
\text { b-PEO }\end{array}$ & 23 & NA & NA & NA \\
\hline $\begin{array}{c}\mathbf{1 0 0 \% m o l ~ P B D - ~} \\
\text { b-PEO }\end{array}$ & 0 & & NA \\
\hline
\end{tabular}


Differential scanning calorimetry (Figure 3) was performed on dilute aqueous dispersions of pure and hybrid DPPC/ PBD-b-PEO vesicles to probe their thermotropic behaviour. The thermograms show two distinct phase transitions: the DPPC pre-transition and the main phase transition.[39][40] The pre-transition ripple phase, $\left(\mathrm{P}_{\beta}\right)$, is visible for $\mathrm{T}<41{ }^{\circ} \mathrm{C}$ up to a copolymer content of $35 \% \mathrm{~mol}$. The data show that the DPPC main transition temperature from the gel to the liquid crystalline phase, occurs at $\mathrm{T} \approx 41^{\circ} \mathrm{C}[41]$ and it is not affected by the presence of the block copolymer. No melting transition is observed for the $65 \% \mathrm{~mol}$ hybrid vesicle and for the pure block copolymer system. Moreover, the melting enthalpy shows a linear decrease as a function of the lipid content. The persistence of both gel and ripple phases up to $65 \% \mathrm{~mol} / \mathrm{mol}$ of copolymer, the negligible decrease of $T_{m}$, and the linear relationship between melting enthalpy and lipid content, clearly indicate a lateral phase separation, where domains of pure DPPC coexist with domains of block copolymer not involved in the phase transition. As the block copolymer content increases, the DPPC melting domains possibly decrease in number and/or size. As the inset of Figure 3 shows, from the intercept of $\Delta \mathrm{H}$ vs the phospholipid content, we identify a threshold amount of DPPC for the observation of the phase transition, corresponding to $20 \% \mathrm{w} / \mathrm{w}$, which can be interpreted as due to partial miscibility between the copolymer and the phospholipid. On the other side, we can interpret the linear dependence of the melting enthalpy on DPPC content, as consistent with the presence of a layer lipid molecules, located at the grain boundaries of the different domains in the bilayers whose packing order is disrupted by the proximity with copolymer domains. Therefore, these interfacial lipids will not contribute to melting. With the assumption that the copolymer domains are disk-like with a radius $\mathrm{R}_{\mathrm{cop}}$, the dependence of the melting enthalpy on the copolymer content can be described with the following equation (see SI for derivation):

$$
\Delta H_{m}=\Delta H_{m}^{0}\left[1-\chi\left(1+\frac{\left(R_{c o p}+d\right)^{2}}{R_{c o p}^{2}}\right)\right]
$$


With $\Delta H_{m}^{0}$ being the melting enthalpy in the absence of copolymer, and $d$ the thickness of the region of DPPC perturbed by the presence of PBD-b-PEO, and $\chi$ is the mole fraction of the copolymer. From a linear fit of the experimental $\Delta H_{m}$ values, we determine a typical size for the copolymer domains of $230 \mathrm{~nm}^{2}$, assuming a perturbation thickness of $1.6 \mathrm{~nm}$, corresponding to two molecules of DPPC with a headgroup area of $0.5 \mathrm{~nm}^{2}$. [28]

In summary, the DLS study on vesicles' dispersions shows that hybrid lipid/copolymer vesicles are present for all the lipid/copolymer ratios investigated. From DSC data we infer that in these vesicles the lipid and the copolymer show only partial miscibility, with lateral phase separation into lipid and copolymer rich regions. To gain deeper insight on the miscibility between DPPC and PBD-b-PEO, we investigated mixed monolayers at the air/water interface, as detailed in the following section.

\subsection{Hybrid monolayers at the air-liquid interface}

According to previous works [42] [43] the monolayer's properties at the air/water interface can elucidate the bilayer's ones in the vesicles. In order to achieve a deep knowledge of the hybrid DPPC/PBD-b-PEO systems, monolayers at the air/water interface were investigated at the same lipid/copolymer molar ratio $(0,10 \%, 35 \%, 65 \%$ and 100\%mol PBD-b-PEO) of the hybrid vesicles. 

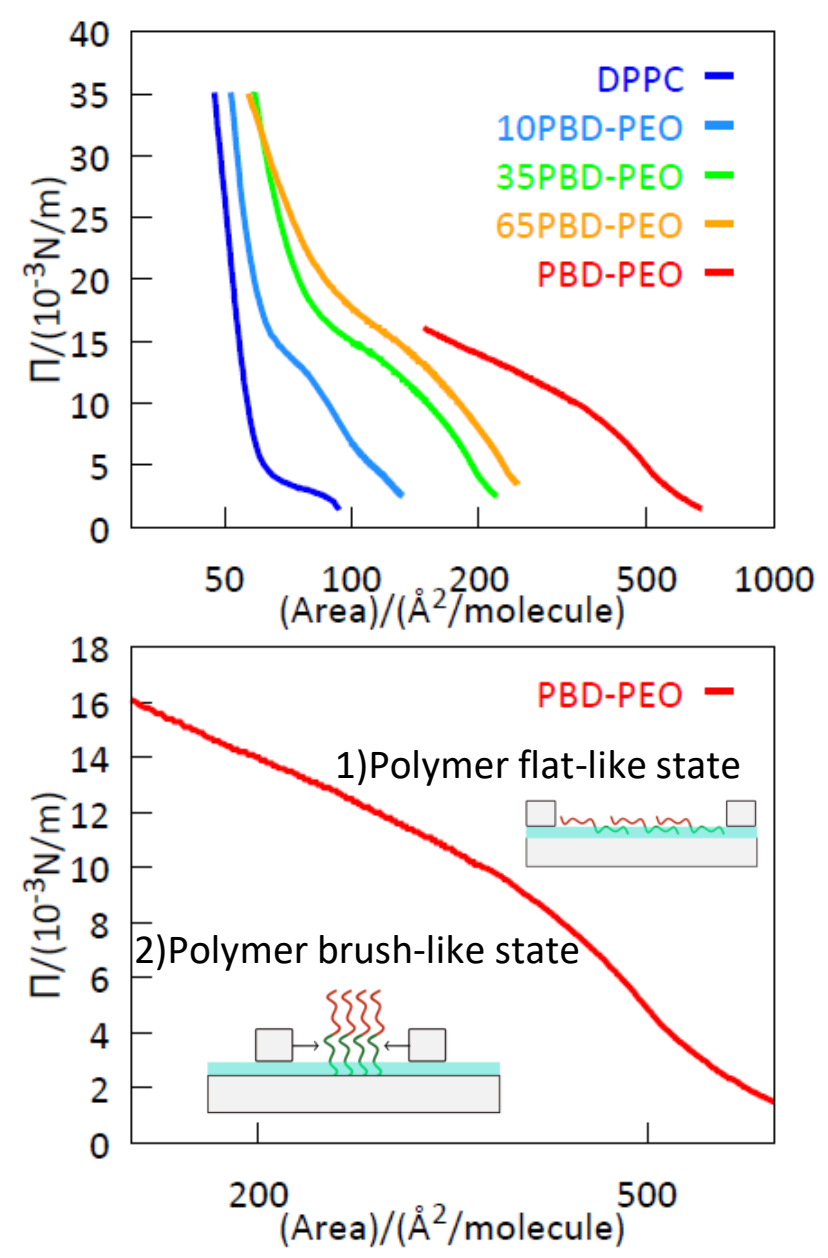

Figure 4. П-A isotherms of 0, 10\%, 35\%, 65\%, 100\% (top) PBD-b-PEO:DPPC monolayers in MilliQ water subphase and extended 100\% PBD-b-PEO:DPPC isotherm (bottom). The data refer to the first compression performed at $T=21^{\circ} \mathrm{C}$, the complete data of the two compression/expansion cycles are reported in the SI. Note the logarithmic $x$-axis.

The phase behavior of the hybrid lipid-copolymer monolayers at the air/liquid interface was investigated using the Langmuir trough technique, with pure water as a subphase, see data in Fig. 4. Two isothermal cycles, performed at $\mathrm{T}=21^{\circ} \mathrm{C}$, show a good stability of the system, with only the pure block copolymer showing loss of material (full isothermal compression/expansion cycles are given in Figure S3 in the SI). The DPPC monolayer shows the typical feature of the П-A isotherm for this lipid: as the area per molecule was reduced, an increasing packing of the homogeneous liquid-expended (LE) phase occurs; at an area per molecule of about $60 \AA^{2}$ the 
typical plateau corresponding to the coexistence of a LE/LC phases and a highly ordered liquidcondensed (LC) phase was observed; finally at a small value of the area per molecule (50 $\left.\AA^{2}\right)$ only the LC phase is present. Considering the DPPC headgroup area of $50 \AA^{2}$ the corresponding bilayer's pressure can be calculated trough the DPPC monolayer П-A curve giving a value of 27 $\mathrm{mN} / \mathrm{m}$.

For PBD-PEO, the surface pressure isotherm spans over a larger range of molecular areas due to its bigger size. The copolymer adopts two preferential conformations, with the transitional conformation behavior typical for block copolymers[44]: at a very large area per molecule $(\Pi<$ $10 \mathrm{mM} / \mathrm{m}$ ) the block copolymer takes a flat-like state while a brush-like state appears at a high pressure $(\Pi>10 \mathrm{mM} / \mathrm{m})$. Indeed, the transition appears at the critical pressure of the hydrophilic block, $\Pi_{0}=10 \mathrm{mM} / \mathrm{m}$ for PEO. At surface pressure higher than $\Pi_{0}$, the PEO block is squeezed out from the interface and the brush state is formed: this regime is dominated by entangling interactions at moderate pressure and a terminal repulsive regime at high packing.[45] The copolymer monolayer could not be compressed to a surface pressure beyond $20 \mathrm{mN} / \mathrm{m}$, while previous works reported a maximum surface pressure of $30 \mathrm{mN} / \mathrm{m}$. [46][47] We assume that this difference is a purely instrumental limit due to the ratio between the deposited material and the minimum available area for the compression of the monolayer. As shown in Figure 4, the hybrid monolayers show an intermediate behavior with respect to the two pure systems. In particular, all of them present the flat-like to brush-like state transition typical of the copolymer and the steep increase of the surface pressure at low area per molecule typical of DPPC and the isotherms shift toward larger areas with respect to DPPC with increasing amounts of copolymer in the mixture. From the experimentally measured $\Pi$-A profiles the surface compressive modulus, $E_{s}$, of the monolayer was determined via the following expression[48]: 


$$
E_{S}=\frac{1}{C_{S}}=-A\left(\frac{d \Pi}{d A}\right)_{T}
$$

Where $\mathrm{C}_{\mathrm{s}}$ is the monolayer compressibility, $\mathrm{A}$ is the area per unit molecule at a given lateral stress and $\Pi$ is the corresponding lateral pressure. The dependence of $E_{s}$ on the surface pressure (Fig. 5) shows that the film elasticity is dominated by the phospholipid at high lateral pressure, with values of $E_{\mathrm{s}}$ close to $0.1 \mathrm{~N} / \mathrm{m}$, suggesting that the confinement of the polymer chains induces the monolayers' stiffness in a similar way as the lipopolysaccharides at the air-water interface[49][48]. Interestingly, the presence of the block-copolymer causes a softening of the hybrid monolayers depending on its content probably because it increases the mean distance between DPPC molecules. At low lateral pressure the elasticity of the film is dominated by the properties of the block copolymer: a clear minimum, characteristic of phase-transitions[50], is found at $\Pi \sim 15$ $\mathrm{mN} / \mathrm{m}$ and is ascribed to a conformational change of the copolymer.

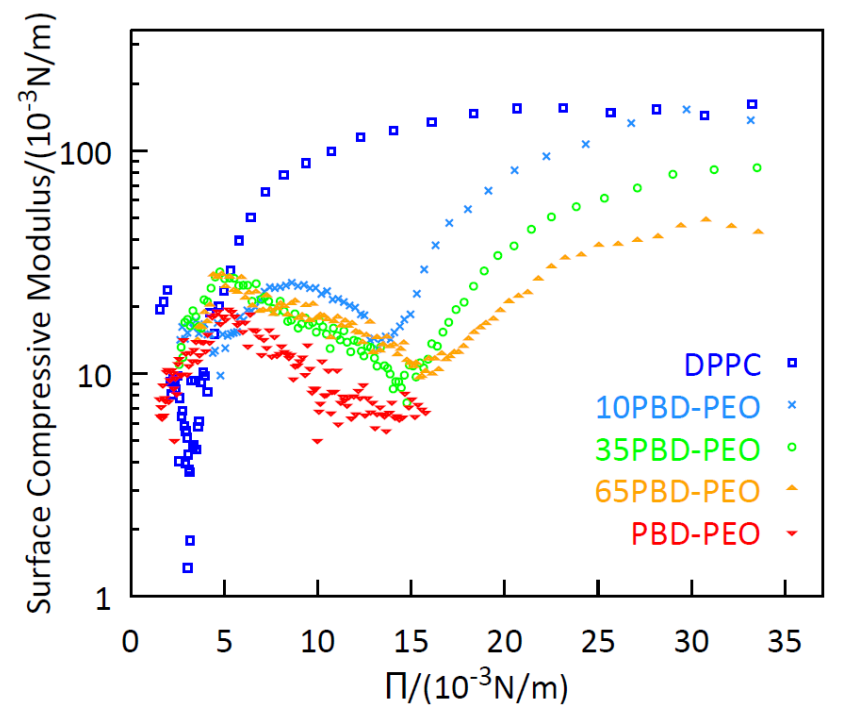

Figure 5. Surface compressive modulus of $0 \%, 10 \%, 35 \%, 65 \%$ and 100\% mol PBD-b-PEO:DPPC isotherms of the first compression (the surface compressive modulus of the isotherms of the complete cycles are in the SI). 
The surface excess, $\Gamma$, at the air-liquid interface was monitored as a function of lateral pressure by multi-angle ellipsometry combined with a Langmuir Through, displayed in the Figure 6 . The ellipsometric data are given in the supporting information in Fig. S6.

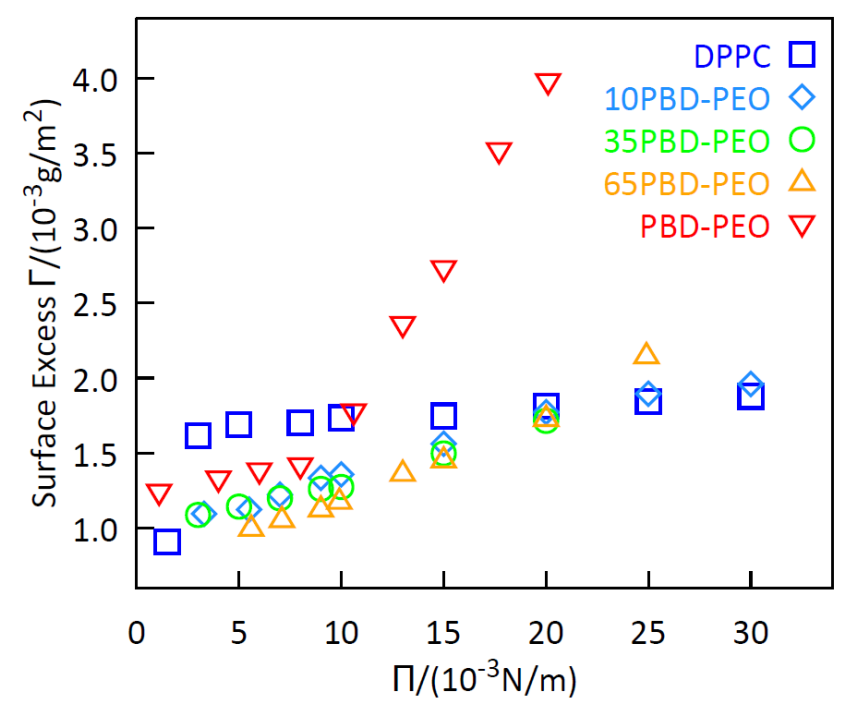

Figure 6. Surface excess $\Gamma$ dependence from the lateral pressure $\Pi$ for 0,10\%,35\%, 65\% and 100\% mol PBD-b-PEO:DPPC monolayers.

Figure 6 displays the Surface Excess $\Gamma$ of the monolayers at the air/water interface at different lateral pressures $\Pi(0-30 \mathrm{mN} / \mathrm{m})$. Pure DPPC monolayer has a sudden increase of $\Gamma$, from 0.8 $\mathrm{mg} / \mathrm{m}^{2}$ to $1.6 \mathrm{mg} / \mathrm{m}^{2}$, in the range of $0-5 \mathrm{mN} / \mathrm{m}$, then it presents a slight increase until $30 \mathrm{mN} / \mathrm{m}$. The surface excess of the pure PBD-PEO monolayer, on the contrary, increases slightly in the range $0-10 \mathrm{mN} / \mathrm{m}\left(1.3 \mathrm{mg} / \mathrm{m}^{2}-1.7 \mathrm{mg} / \mathrm{m}^{2}\right)$ and then it has a sudden increase reaching a value of 4 $\mathrm{mg} / \mathrm{m}^{2}$. Hybrid monolayers have a Surface Excess $\Gamma$ that reflects the pure copolymer monolayer Surface Excess until the critical value $\Pi=10 \mathrm{mN} / \mathrm{m}$, where the trend becomes the same as the phospholipid. The surface excess $\Gamma$ presents a non-linear profile at a constant lateral pressure: hybrid monolayers have a surface excess lower than the pure lipid and copolymer monolayers, when the surface pressure is $\Pi=10 \mathrm{mN} / \mathrm{m}$, while with the increasing of the surface pressure ( $\Pi$ $=20 \mathrm{mN} / \mathrm{m}$ ) their surface excess assumes a constant value like the DPPC, indicating that the 
monolayers became more rigid because of the repulsive interactions between the lipid tails. We can conclude that at low-pressure values $(\Pi<10 \mathrm{mN} / \mathrm{m})$ the interactions between the copolymer chains dominate at the interface, while with the increasing pressure $(\Pi>10 \mathrm{mN} / \mathrm{m})$ the repulsion between the phospholipid tails determines the interfacial behaviour.

The ensemble of data on free-standing bilayers and monolayers prove that the DPPC/PBD-PEO system forms hybrid monolayer and lamellar systems, with partial miscibility of the phospholipid in a copolymer rich-phase. For copolymer contents from $10 \%$ to $65 \% \mathrm{~mol}$, distinct regions of lipid and copolymer phase are formed within the bilayers.

Therefore, DPPC-PBD-PEO systems appear as interesting hybrid materials combining characteristics of both building blocks (e.g. thermo-responsivity, lateral compressibility, etc.). To further extend this investigation, we addressed the formation of hybrid supported bilayers on a hydrophilic solid substrate.

\subsection{Hybrid Supported Copolymer-Lipid bilayers}

Solid-supported bilayers were prepared by vesicle fusion on a hydrophilic $\mathrm{SiO}_{2}$ substrate at a constant temperature $\mathrm{T}=40^{\circ} \mathrm{C}$, close to the gel to liquid-crystalline phase transition temperature $\left(\mathrm{T}_{\mathrm{m}}=41^{\circ} \mathrm{C}\right)$ of the phospholipid. QCM-D was used to follow the vesicle adsorption and fusion, [51], measurements were performed at $\mathrm{T}=40^{\circ} \mathrm{C}$ in $\mathrm{NaCl} 0.1 \mathrm{M}$, and $\mathrm{CaCl}_{2} 10 \mathrm{mM}$. QCM-D data shown in Fig. 7 highlight that the vesicles adsorption and fusion take place only in the presence of DPPC. In contrast, no film is formed when the crystal is exposed to a solution of pure blockcopolymer, consistent with the literature [52]. In particular, pure DPPC systems are characterized by frequency shifts and dissipation typical of a supported lipid bilayer, that is, around $-30 \mathrm{~Hz}$ 
frequency shift and low dissipation, consistent with a homogeneous SLB firmly coupled to the support.[53]

Conversely, hybrid systems are characterized by higher frequency shifts and dissipation, indicating a more hydrated membrane with a lower coupling with the sensor surface. This evidence clearly proves that a hybrid membrane is formed on the support, with structural/viscoelastic properties which differ from both the pure DPPC and the pure copolymer. In particular, the lower coupling of the membrane with the support can be assigned to the thickness mismatch between the copolymer and the lipid moieties, which might induce the formation of localized lifted areas partially detached from the surface. This characteristic is particularly attractive for specific application of the hybrid SLB, for instance the insertion/reconstitution of functional membrane proteins, which is a generally challenging task in lipid SLBs, due to the attachment of the lipid membrane to the underlying support. 


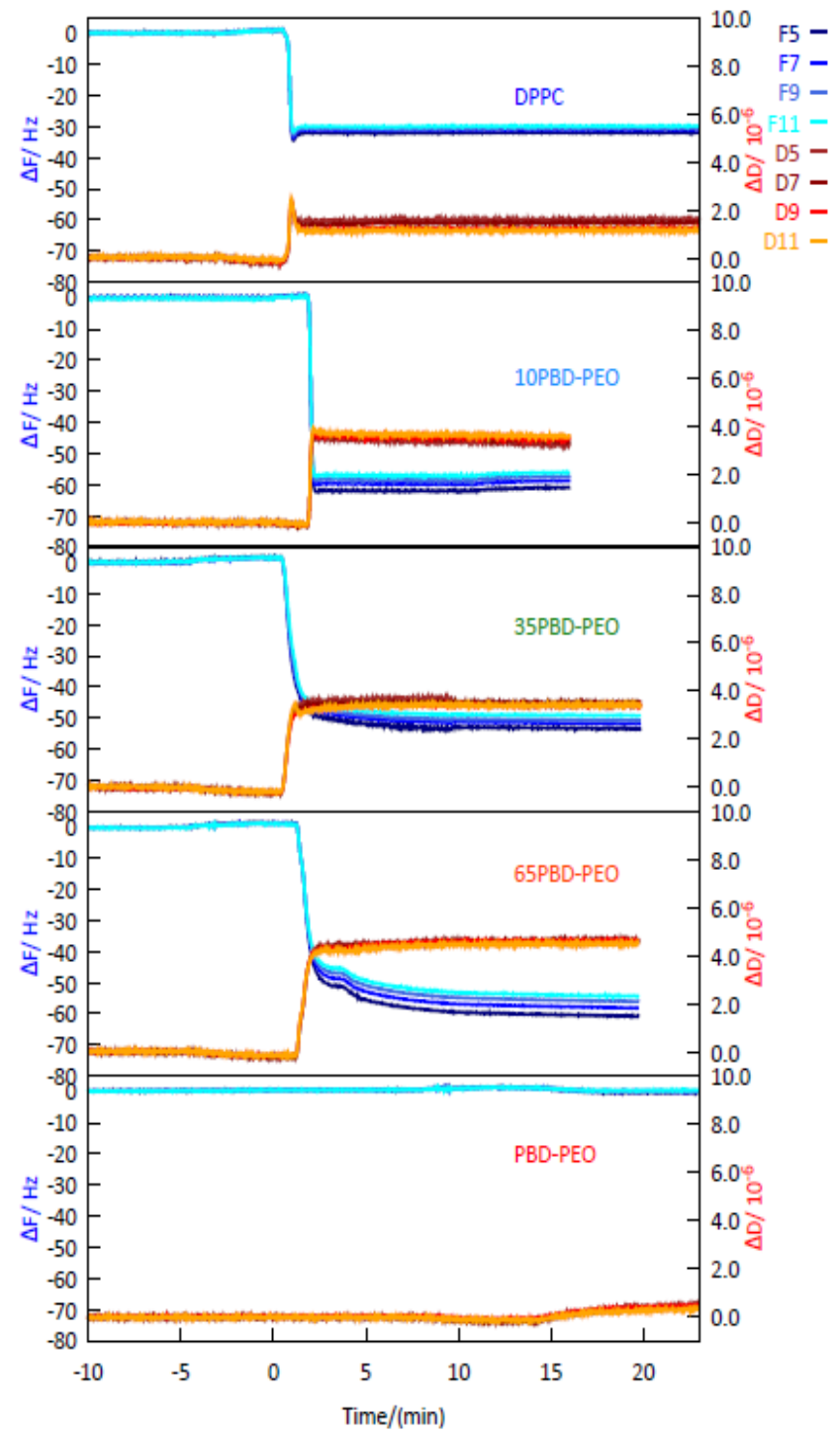

Figure 7. QCMD's measurements of the adsorption and desorption of 0, 10\%, 35\%, 65\% and 100\% mol PBD-b-PEO:DPPC in $\mathrm{NaCl} 0.1 \mathrm{M}$ and $\mathrm{CaCl}_{2} 10 \mathrm{mM}$.

To quantitatively estimate the hydrated mass of the bilayer, we applied the Sauerbrey relation [35], which describes purely elastic responses and can be safely applied when $\Delta \mathrm{D} / \Delta \mathrm{f}<<0.4 \times 10^{-6} \mathrm{~Hz}^{-}$ ${ }^{1}[54]$ (for the plot see Figure 8). Consistently with the qualitative observations above discussed, the adsorbed mass for the pure copolymer is negligible; for DPPC it is estimated as $0.5 \mu \mathrm{g} / \mathrm{cm}^{2}$, which is consistent with a homogeneous coverage of the support by the lipid membrane[8]; the hybrid films exhibit the largest adsorbed mass $\left(1 \mu \mathrm{g} / \mathrm{cm}^{2}\right)$, attributable to the efficient thin film 
formation and to the large coupling with water of the copolymer and/or the inclusion of the polymer in the bilayer structure.

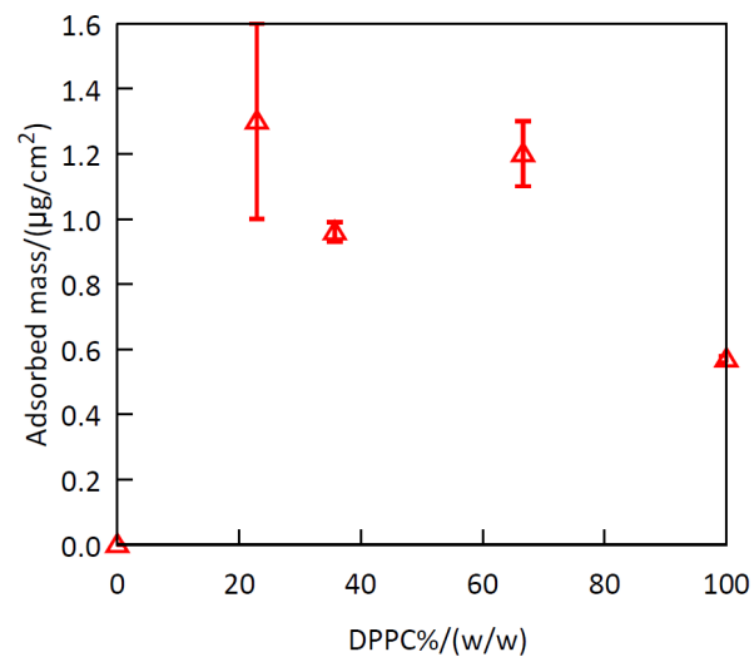

Figure 8. Adsorbed mass estimate with QCMD technique at different DPPC concentrations (w/w).

The thickness of solid supported bilayer was determined via multi-angle ellipsometric experiment, using classical electromagnetic theory in conjunction with parallel layer model consisting of a silicon/silicon oxide/bilayer/water structure. The treatment assumes that the total sample consists of parallel slabs, each is a uniform material of homogeneous composition described by a single set of optical constants (refractive index $\mathrm{n}$ and thickness d). In order to reduce the number of parameters, the thickness of the $\mathrm{SiO}_{2}$ layer was determined on a clean substrate and kept constant for the analysis of the SLB samples. The obtained values of film thickness and refractive index are reported in Table 2. A pure polymer layer on the silicon substrate was not prepared, not having observed absorption with the QCM-D. The pure DPPC and the hybrid SLBs exhibit very similar thicknesses of approx. $6.6 \mathrm{~nm}$ and refractive index of 1.49. The results confirm the formation of a solid supported bilayer for all the investigated samples.[22] The minimal change in thickness as a function of the copolymer content indicates that the adsorbed dry mass remains constant within the investigated sample series. This result is in good agreement with the QCM-D results (Figure 
8), which show a moderate increase of mass with the presence of the copolymer, which we ascribe to the water coupled to the hydrophilic moieties of the macromolecule.

Table 2. Table of estimated thickness for the parallel-slabs optical model.

\begin{tabular}{ccc}
\hline Layer & Thickness (nm) & Refractive index \\
\hline Air & $\infty$ & 1.00 \\
\hline Water & $\infty$ & 1.33 \\
\hline DPPC & $6.3 \pm 0.3$ & $1.495 \pm 0.002$ \\
\hline $\begin{array}{c}\text { 10\% mol PBD-b- } \\
\text { PEO:DPPC }\end{array}$ & $6.8 \pm 0.3$ & $1.488 \pm 0.003$ \\
\hline $\begin{array}{c}\text { 35\% mol PBD-b- } \\
\text { PEO:DPPC }\end{array}$ & $6.5 \pm 0.3$ & $1.480 \pm 0.003$ \\
\hline $\begin{array}{c}\text { 65\% mol PBD-b- } \\
\text { PEO:DPPC }\end{array}$ & $6.6 \pm 0.3$ & $1.477 \pm 0.003$ \\
\hline SiO & & 1.46 \\
\hline Si & $2.9 \pm 0.3$ & 3.98 \\
\hline
\end{tabular}

Confocal laser scanning microscopy (CLSM) was employed to evaluate the formation and the morphology of mixed bilayers generated by vesicles rupture and fusion on a transparent support of borosilicate. In order to investigate the morphology of the film at the micro-scale, and in particular the localization of the lipid and of the copolymer regions, we used two different fluorescent probes: a rhodamine-modified copolymer (RhodPBD-b-PEO) and a lipid $\beta$-bodiby dye. The dyes differ for their relative affinity toward the lipid and copolymer phases and they have an amphiphilic nature, so they spontaneously embed in vesicles' bilayer. Moreover, they are characterized by a well separated absorption and emission spectra: the rhodamine is excited at a wavelength $561 \mathrm{~nm}$, and its emission spectra lies in the range of $571 \mathrm{~nm}-630 \mathrm{~nm}$; in contrast, $\beta$ bodipy excitation wavelength is $488 \mathrm{~nm}$ and it emits in the range $488 \mathrm{~nm}-530 \mathrm{~nm}$. The different 
spectral properties allow the simultaneous monitoring of the distribution of the two species. CLSM experiments were also performed on pure samples of DPPC and PBD-b-PEO doped with the twofluorescent dye as control measurements reported in SI. All the CLSM images highlight a uniform fluorescent probe lateral distribution, suggesting the successful supported bilayers formation on slide by the vesicles rupture and fusion at the microscale. The CLSM images of hybrid samples show clear red and green patterns, evidencing a phase separation in lipid and copolymer rich regions at the microscale. From a qualitative point of view, a clear correlation appears between the relative amount of copolymer and lipid in the mixed membrane in the resulting phase separation extent at the micron-scale in lipid- and copolymer- rich regions, as can be visualized from the CLSM images (Figure 9).

$10 \% \mathrm{~mol}$ PBD-PEO

$35 \% \mathrm{~mol}$ PBD-PEO

$65 \% \mathrm{~mol}$ PBD-PEO
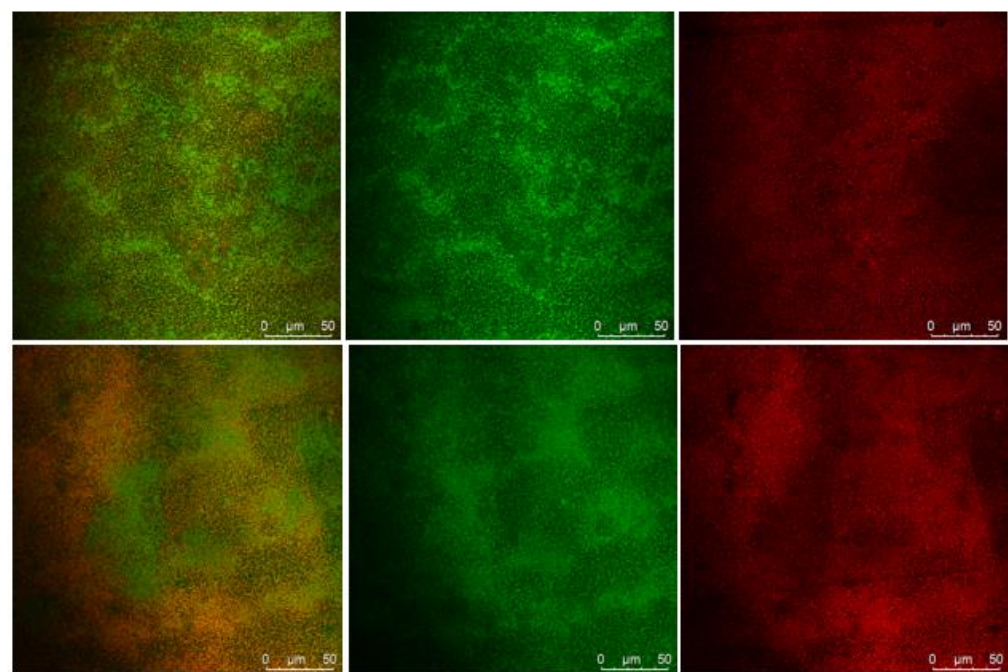

Figure 9. CLSM images for hybrid 10\%, 35\% and 65\% mol PBD-b-PEO:DPPC SLBs. Merged and single channels PBD(1200)-b$P E O(600)+$ rhodamine excitation wavelength $561 \mathrm{~nm}$, emission wavelength $571 \mathrm{~nm}-630 \mathrm{~nm}$ (red); $\beta$-bodipy excitation wavelength $488 \mathrm{~nm}$, emission wavelength $488 \mathrm{~nm}-530 \mathrm{~nm}$ (green). 
In conclusion, all the CLSM images highlight the formation of a micron scale defect-free (lack of uncovered areas and/or vesicles) thin film with a microscopic phase separation into copolymer and lipid-rich regions, suggesting the successful supported bilayers formation on the slide by vesicles rupture and fusion at the microscale. From the study of simple systems constituted of hybrid vesicles and monolayers to the more complicated hybrid supported bilayers a phase separation is highlighted at the nano- and the micro-scale, where hybrid materials combine the inherent properties of the DPPC and PBD-PEO component.

\section{SUMMARY AND CONCLUSION}

In this work, a comprehensive physicochemical characterization of hybrid lipid-copolymer systems - made of DPPC phospholipid and PBD-b-PEO amphiphilic block copolymer - is presented. The properties of the aqueous vesicle solutions, of the monolayer at the air/water interface, and of the solid supported bilayers were investigated. DSC proved the successful formation of the hybrid vesicles, clearly showing non-mixing behaviour. All the data (optical ellipsometry, QCM-D,) confirm HSLB formation upon vesicles rupture and fusion on a silicon substrate with an effective incorporation of the copolymer in the lipid layer. The 2D characterization of the mixed membrane at the micron-scale was estimated using confocal laser scanning microscopy (CLSM). It confirms the successful formation of HSLBs also on a borosilicate cover-glass as a support, showing the presence of a lateral phase separation in distinct lipid and copolymer rich-regions at the micron-scale, which is qualitatively dependent on the relative amounts of the two components. Microphase separation has been evidenced in both the hybrid vesicles and supported lipid bilayer where has been in the case of GUVs. Polymer inclusion 
in lipid systems expands the physicochemical properties of the lipid systems: compression isotherms indicate the realization of softer films with the copolymer in the monolayer. The properties dependence of the mixtures on the relative amounts of the two components opens the possibility to fine-tuning the properties of the hybrid, by simply varying the relative lipidcopolymer composition. Overall, these results represent a first physicochemical and structural characterization of DPPC/PBD-b-PEO HLSBs, which will be necessary for the future exploitation of HLSBs both in fundamental studies and in applications, i.e. proteins or nanoparticles incorporation in the membrane of the bilayers.

\section{ASSOCIATED CONTENT}

\section{Supporting Information.}

The following files are available free of charge.

Supporting data: histograms of the intensity distribution for vesicles in water; derivation of the equation 4; complete $\Pi$-A isothermal cycles (Figure S3); Surface compressive modulus for the complete isothermal cycles (Figure S4); refractive index increments for pure DPPC and PBD-bPEO solutions (Figure S5); ellipsometric studies for all the monolayers (Figure S6); QCM-D sensed mass for the supported bilayers (Figure S7); ellipsometric studies for all the supported bilayers (Figure S8) and CSLM images for pure DPPC and PBD-b-PEO bilayers (Figure S9).

\section{AUTHOR INFORMATION}

\section{Corresponding Author}

* Give contact information for the author(s) to whom correspondence should be addressed.

\section{Present Addresses}

$\dagger$ If an author's address is different than the one given in the affiliation line, this information may be included here. 


\section{Author Contributions}

The manuscript was written through contributions of all authors. All authors have given approval to the final version of the manuscript. $\$$ These authors contributed equally. (match statement to author names with a symbol)

\section{ACKNOWLEDGEMENTS}

The partnership of soft condensed matter (PSCM) at the ILL is thanked for providing the microcalorimeter, the ellipsometer, and the quartz-crystal microbalance. A.B., D.B. and C. M. acknowledge CSGI for the partial financial support.

\section{REFERENCES}

[1] A. Akbarzadeh, R. Rezaei-sadabady, S. Davaran, S. W. Joo, and N. Zarghami, "Liposome: classification , preparation, and applications," Nanoscale Res. Lett., vol. 8, pp. 1-9, 2013.

[2] Y. Malam, M. Loizidou, and A. M. Seifalian, "Liposomes and nanoparticles: nanosized vehicles for drug delivery in cancer,” Trends Pharmacol. Sci., vol. 30, pp. 592-599, 2009.

[3] G. M. El Maghraby, B. W. Barry, and A. C. Williams, "Liposomes and skin: From drug delivery to model membranes," Eur. J. Pharm. Sci., vol. 34, pp. 203-222, 2008.

[4] Y.-H. M. Chan and S. G. Boxer, "Model membrane systems and their applications," Curr. Opin. Chem. Biol., vol. 11, pp. 581-587, 2007.

[5] M. Kang, M. Tuteja, A. Centrone, D. Topgaard, and C. Leal, "Nanostructured Lipid-Based 
Films for Substrate-Mediated Applications in Biotechnology," Adv. Funct. Mater., vol. 28, no. 9, p. 1704356, Feb. 2018.

[6] J. Kowal, D. Wu, V. Mikhalevich, C. G. Palivan, and W. Meier, "Hybrid Polymer - Lipid Films as Platforms for Directed Membrane Protein Insertion,” Langmuir, vol. 31, pp. 4868$4877,2015$.

[7] R. P. Richter and A. R. Brisson, "Following the Formation of Supported Lipid Bilayers on Mica : A Study Combining AFM, QCM-D, and Ellipsometry,” Biophys. J., vol. 88, no. 5, pp. 3422-3433, 2005.

[8] C. Montis, Y. Gerelli, G. Fragneto, T. Nylander, P. Baglioni, and D. Berti, "Nucleolipid bilayers: A quartz crystal microbalance and neutron reflectometry study," Colloids Surfaces B Biointerfaces, vol. 137, pp. 203-213, 2016.

[9] D. E. Discher and F. Ahmed, "Polymersomes," Annu. Rev. Biomed. Eng., vol. 8, pp. 32341, 2006.

[10] B. M. Discher et al., "Polymersomes: Tough Vesicles Made from Diblock Copolymers," Science (80-. )., vol. 284, pp. 1143-1147, 1999.

[11] L. Messager, J. Gaitzsch, L. Chierico, and G. Battaglia, "Novel aspects of encapsulation and delivery using polymersomes," Curr. Opin. Pharmacol., vol. 18, no. 1, pp. 104-111, 2014.

[12] Y. Kim et al., "Polymersome delivery of siRNA and antisense oligonucleotides," J. Control. Release, vol. 134, no. 2, pp. 132-140, 2009.

[13] Y. Zhu, B. Yang, S. Chen, and J. Du, "Polymer vesicles: Mechanism , preparation , 
application, and responsive behavior," Prog. Polym. Sci., vol. 64, pp. 1-22, 2017.

[14] R. Chandrawati and F. Caruso, "Biomimetic liposome- and polymersome-based multicompartmentalized assemblies," Langmuir, vol. 28, no. 39, pp. 13798-13807, 2012.

[15] E. Rideau, R. Dimova, P. Schwille, F. R. Wurm, and K. Landfester, "Liposomes and polymersomes: a comparative review towards cell mimicking," Chem. Soc. Rev., vol. 47, no. 23 , pp. $8572-8610,2018$.

[16] M. Schulz and W. H. Binder, "Mixed Hybrid Lipid/Polymer Vesicles as a Novel Membrane Platform," Macromol. Rapid Commun., vol. 36, pp. 2031-2041, Dec. 2015.

[17] T. P. T. Dao et al., "Phase Separation and Nanodomain Formation in Hybrid Polymer/ Lipid Vesicles," ACS Macro Lett., vol. 4, pp. 182-186, 2015.

[18] W. Shen, J. Hu, and X. Hu, "Impact of amphiphilic triblock copolymers on stability and permeability of phospholipid/polymer hybrid vesicles," Chem. Phys. Lett., vol. 600, pp. 5661, 2014.

[19] T. P. T. Dao et al., "Modulation of phase separation at the micron scale and nanoscale in giant polymer/lipid hybrid unilamellar vesicles (GHUVs)," Soft Matter, vol. 13, no. 3, pp. 627-637, 2017.

[20] M. Schulz et al., "Hybrid lipid/polymer giant unilamellar vesicles: effects of incorporated biocompatible PIB - PEO block copolymers on vesicle properties," Soft Matter, vol. 7, pp. 8100-8110, 2011.

[21] D. L. Gettel et al., "Mixing, Diffusion, and Percolation in Binary Supported Membranes Containing Mixtures of Lipids and Amphiphilic Block Copolymers," J. Am. Chem. Soc, 
vol. 136, pp. 10186-10189, 2014.

[22] M. M. Virk, B. Hofmann, and E. Reimhult, "Formation and Characteristics of LipidBlended Block Copolymer Bilayers on a Solid Support Investigated by Quartz Crystal Microbalance and Atomic Force Microscopy,” Langmuir, vol. 35, pp. 739-749, 2019.

[23] W. F. Paxton, P. T. McAninch, S. H. R. Shin, and M. T. Brubach, "Adsorption and fusion of hybrid lipid/polymer vesicles onto 2D and 3D surfaces," Soft Matter, vol. 14, pp. 81128118, 2018.

[24] S. Khan, M. Li, S. P. Muench, L. J. C. Jeuken, and P. A. Beales, "Durable proteo-hybrid vesicles for the extended functional lifetime of membrane proteins in bionanotechnology," Chem. Commun., vol. 52, pp. 11020-11023, 2016.

[25] P. A. Beales, S. Khan, S. P. Muench, and L. J. C. Jeuken, "Durable vesicles for reconstitution of membrane proteins in biotechnology," Biochem. Soc. Trans., vol. 45, no. 1, pp. 15-26, 2017.

[26] A. Salvatore, C. Montis, D. Berti, and P. Baglioni, "Multifunctional Magnetoliposomes for Sequential Controlled Release," ACS Nano, vol. 10, p. 7749-7760, 2016.

[27] R. P. Brinkhuis, F. P. J. T. Rutjes, and J. C. M. van Hest, "Polymeric vesicles in biomedical applications," Polym. Chem., vol. 2, pp. 1449-1462, 2011.

[28] J. F. Nagle and S. Tristram-Nagle, "Structure of lipid bilayers," Biochim. Biophys. Acta Rev. Biomembr., vol. 1469, no. 3, pp. 159-195, 2000.

[29] C. Magnani et al., "Hybrid vesicles from lipids and block copolymers: Phase behavior from the micro- to the nano-scale," Colloids Surfaces B Biointerfaces, vol. 168, pp. 18-28, Aug. 
2018.

[30] J. P. Reeves and R. M. Dowben, "Formation and Properties of Thin-walled Phospholipid Vesicles," J. Cell. Physiol., vol. 73, pp. 49-60, 1969.

[31] D. V Malakhov and M. K. A. Khatwa, "Constructing a self-consistent integral baseline by using cubic splines," J. Therm. Anal. Calorim., vol. 87, pp. 595-599, 2007.

[32] S. W. Provencher, "Contin: a general purpose constrained regularization program for inverting noisy linear algebraic and integral equations," Comput. Phys. Communcations, vol. 27, pp. 229-242, 1982.

[33] M. Newville et al., "Imfit/lmfit-py 1.0.0,” Dec. 2019.

[34] S. J. Byrnes, "Multilayer optical calculations," pp. 1-20, 2019.

[35] G. Sauerbrey, "Verwendung von Schwingquarzen zur Wägung dünner Schichten und zur Mikrowägung," Zeitschrift für Phys., vol. 155, pp. 206-222, 1959.

[36] J. A. D. E. Feijter, J. Benjamins, and F. A. Veer, "Ellipsometry as a Tool to Study the Adsorption Behavior of Synthetic and Biopolymers at the Air- Water Interface," Biopolymers, vol. 17, pp. 1759-1772, 1978.

[37] F. Szoka, "Comparative properties and methods of preparation of lipid vesicles (liposomes)," Ann. Rev. Biophys. Bioeng., vol. 9, pp. 467-508, 1980.

[38] J. E. Bartenstein, J. Robertson, G. Battaglia, and W. H. Briscoe, "Stability of polymersomes prepared by size exclusion chromatography and extrusion," Colloids Surfaces A Physicochem. Eng. Asp., vol. 506, pp. 739-746, 2016. 
[39] R. N. A. H. Lewis, W. Pohle, and R. N. Mcelhaney, "The Interfacial Structure of Phospholipid Bilayers: Differential Scanning Calorimetry and Fourier Transform Infrared Spectroscopic Studies of 1, 2-Dipalmitoyl-sn-Glycero-3-Phosphorylcholine and Its Dialkyl and Acyl-Alkyl Analogs," Biophys. J., vol. 70, pp. 2736-2746, 1996.

[40] K. A. Riske, R. P. Barroso, C. C. Vequi-Suplicy, R. Germano, V. B. Henriques, and M. T. Lamy, "Lipid bilayer pre-transition as the beginning of the melting process," Biochim. Biophys. Acta, vol. 1788, pp. 954-963, 2009.

[41] S. Mabrey and J. M. Sturtevant, "Investigation of phase transitions of lipids and lipid mixtures by high sensitivity differential scanning calorimetry," Proc. Natl. Acad. Sci. USA, vol. 73, no. 11 , pp. 3862-3866, 1976.

[42] R. C. MacDonald and S. A. Simon, "Lipid monolayer states and their relationships to bilayers," Proc. Natl. Acad. Sci. U. S. A., vol. 84, no. 12, pp. 4089-4093, 1987.

[43] S. Feng, "Interpretation of Mechanochemical Properties of Lipid Bilayer Vesicles from the Equation of State or Pressure - Area Measurement of the Monolayer at the Air - Water or Oil - Water Interface,” Langmuir, vol. 15, pp. 998-1010, 1999.

[44] J. Iyer and P. T. Hammond, "Langmuir Behavior and Ultrathin Films of New LinearDendritic Diblock Copolymers," Langmuir, vol. 15, pp. 1299-1306, 1999.

[45] R. Rodríguez-García, M. Mell, I. López-Montero, J. Netzel, T. Hellweg, and F. Monroy, "Polymersomes: smart vesicles of tunable rigidity and permeability," Soft Matter, vol. 7, pp. 1532-1542, 2011.

[46] R. Matmour, R. Francis, R. S. Duran, and Y. Gnanou, "Interfacial Behavior of Anionically 
Synthesized Amphiphilic Star Block Copolymers Based on Polybutadiene and Poly (ethylene oxide) at the Air / Water Interface," Macromolecules, vol. 38, pp. 7754-7767, 2005.

[47] F. Ahmed, A. Hategan, D. E. Discher, and B. M. Discher, "Block Copolymer Assemblies with Cross-Link Stabilization: From Single-Component Monolayers to Bilayer Blends with PEO-PLA," Langmuir, vol. 19, pp. 6505-6511, 2003.

[48] D. Vollhardt and V. B. Fainerman, "Progress in characterization of Langmuir monolayers by consideration of compressibility," Adv. Colloid Interface Sci., vol. 127, pp. 83-97, 2006.

[49] T. Abraham, S. R. Schooling, T. J. Beveridge, and J. Katsaras, "Monolayer Film Behavior of Lipopolysaccharide from Pseudomonas aeruginosa at the Air-Water Interface," Biomacromolecules, vol. 9, pp. 2799-2804, 2008.

[50] S. Ali, J. M. Smaby, M. M. Momsen, H. L. Brockman, and R. E. Brown, "Acyl ChainLength Asymmetry Alters the Interfacial Elastic Interactions of Phosphatidylcholines," Biophys. J., vol. 74, no. 1, pp. 338-348, 1998.

[51] R. P. Richter, R. Bérat, and A. R. Brisson, "Formation of Solid-Supported Lipid Bilayers: An Integrated View," Langmuir, vol. 22, pp. 3497-3505, 2006.

[52] K. L. Willes, J. R. Genchev, and W. F. Paxton, "Hybrid lipid-polymer bilayers: pHmediated interactions between hybrid vesicles and glass," Polymers (Basel)., vol. 12, no. 4, p. $745,2020$.

[53] C. Montis et al., "Biogenic Supported Lipid Bilayers from Nanosized Extracellular Vesicles," Adv. Biosyst., vol. 2, no. 4, pp. 1-7, 2018. 
[54] I. Reviakine, D. Johannsmann, and R. P. Richter, "Hearing what you cannot see and visualizing what you hear: Interpreting quartz crystal microbalance data from solvated interfaces," Anal. Chem., vol. 83, no. 23, pp. 8838-8848, 2011.

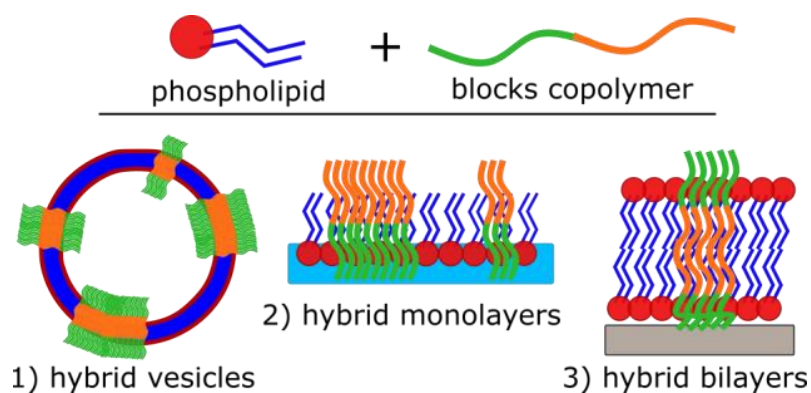

